\title{
Influência do sistema integrado de produção agropecuária no solo e na produtividade de soja e braquiária ${ }^{1}$
}

\author{
João de Andrade Bonetti ${ }^{2}$, Helder Barbosa Paulino ${ }^{3}$, \\ Edicarlos Damacena de Souza ${ }^{4}$, Marco Aurélio Carbone Carneiro ${ }^{5}$, Geanderson Nascimento da Silva ${ }^{5}$
}

\begin{abstract}
Influence of the integrated crop-livestock system on soil and soybean and brachiaria yield

The presence of animals in farming areas can affect soil physical structures depending on grazing intensity. This study aimed to evaluate soil physical attributes, as well as soybean and brachiaria yield, under no-tillage, in an integrated crop-livestock system. Treatments were arranged in a complete randomized blocks design, with three replications, and consisted of different grazing heights $(0.25 \mathrm{~m}, 0.35 \mathrm{~m}$ and $0.45 \mathrm{~m})$ and a no-grazing area. The shoot and root dry biomass of soybean and brachiaria and soybean yield were evaluated. Soil samples were collected from $0-5 \mathrm{~cm}, 5-10 \mathrm{~cm}$ and $10-20 \mathrm{~cm}$ depth layers and the following soil physical attributes were determined: bulk density, total porosity, macroporosity, microporosity, penetration resistance and mean weight diameter of aggregates. Grazing intensities did not affect soil bulk density in any of the analyzed layers. There was a reduction in total porosity after the second grazing cycle, in the $0-5 \mathrm{~cm}$ layer. The mean weight diameter of aggregates was lower in grazed areas, in the $0-5 \mathrm{~cm}$ and $10-20 \mathrm{~cm}$ layers, and an increase in the penetration mechanical resistance was observed in all layers, especially for the $0.25 \mathrm{~m}$ height grazing treatment. The total dry biomass (soybean + brachiaria) and shoot dry biomass of brachiaria were lower in grazed areas. However, the soybean yield was not affected by the different grazing cycles.
\end{abstract}

KEY-WORDS: Glycine max L.; Urochloa ruziziensis; soil aggregation; soil porosity.

\section{INTRODUÇÃO}

O sistema integrado de produção agropecuária em plantio direto (SIPA-PD) é uma alternativa para a recuperação de áreas degradadas em regiões de clima tropical e subtropical, como o Brasil. Essa recupera-

\section{RESUMO}

A presença de animais em áreas de lavoura pode alterar a estrutura física do solo, sendo que a intensidade de pastejo contribui para esse resultado. Este trabalho objetivou avaliar os atributos físicos do solo e a produtividade de soja e braquiária, em sistema integrado de produção agropecuária, sob plantio direto. Os tratamentos foram distribuídos em blocos casualizados, com três repetições, e consistiram de diferentes alturas de manejo do pasto $(0,25 \mathrm{~m}, 0,35 \mathrm{~m}$ e $0,45 \mathrm{~m})$ e uma área sem pastejo. Foi determinada a biomassa seca da parte aérea e raiz da soja e braquiária e a produtividade da soja. Amostras de solo foram coletadas nas camadas de $0-5 \mathrm{~cm}, 5-10 \mathrm{~cm}$ e $10-20 \mathrm{~cm}$ de profundidade, sendo determinados os seguintes atributos físicos: densidade, porosidade total, macroporosidade, microporosidade, resistência à penetração e diâmetro médio ponderado de agregados. As intensidades de pastejo não interferiram na densidade do solo em nenhuma das camadas. Houve redução da porosidade total após o segundo ciclo de pastejo, na camada de $0-5 \mathrm{~cm}$. O diâmetro médio ponderado de agregados foi menor nas áreas pastejadas nas camadas de $0-5 \mathrm{~cm}$ e $10-20 \mathrm{~cm}$ e verificou-se aumento da resistência mecânica à penetração em todas as camadas, principalmente para o pastejo a $0,25 \mathrm{~m}$ de altura. A quantidade de biomassa seca total (soja + braquiária) e biomassa seca da parte aérea da braquiária foram menores nas áreas pastejadas, no entanto, a produtividade da soja não foi influenciada pelos ciclos de pastejo.

PALAVRAS-CHAVE: Glycine max L.; Urochloa ruziziensis; agregação do solo; porosidade do solo.

ção do solo é possível em função da diversidade de culturas e animais que podem ser utilizados nesse sistema. Entretanto, o manejo de animais nas áreas deve ser realizado de maneira adequada, evitando, assim, os efeitos negativos que o pisoteio pode causar ao solo (Hallett et al. 2003, Souza et al. 2010).

1. Trabalho recebido em abr./2014 e aceito para publicação em mar./2015 (http://dx.doi.org/10.1590/1983-40632015v4529625).

2. Universidade Federal do Rio Grande do Sul (UFRGS), Faculdade de Agronomia, Departamento de Solos, Porto Alegre, RS,

Brasil.E-mail: agro.bonetti@gmail.com.

3. Universidade Federal de Goiás (UFG), Unidade Regional de Jataí, Jataí, GO, Brasil. E-mail: helderlino51@yahoo.com.br.

4. Universidade Federal de Mato Grosso (UFMT), Campus Universitário de Rondonópolis, Instituto de Ciências Agrárias e

Tecnológicas, Rondonópolis, MT, Brasil.E-mail: edicarlos@pq.cnpq.br.

5. Universidade Federal de Lavras (UFLa), Departamento de Ciência do Solo, Lavras, MG, Brasil.

E-mails: marcocarbone@dcs.ufla.br, gean.tecnologo@hotmail.com. 
Nesse sentido, a intensidade de pastejo deve ser monitorada de acordo com a capacidade de suporte de carga de cada solo, produção de forragem e demanda de forragem das diferentes raças animais, minimizando, assim, as alterações na sua estrutura física, além de manter o solo coberto com resíduo vegetal, fato importante para a manutenção do plantio direto. O SIPA-PD manejado com altura média de pastejo de $0,20 \mathrm{~m}$ (carga animal de $763 \mathrm{~kg}_{\text {de }} \mathrm{PV} \mathrm{ha}^{-1}$ ) contribui para maior agregação do solo, na camada superficial (Souza et al. 2010, Conte et al. 2011), e não altera a densidade e a porosidade do solo, ao ponto de ocorrer compactação (Conte et al. 2011). Em pastejo intenso, com altura de pasto de $0,10 \mathrm{~m}$ (1.350 kg de PV ha-1), os efeitos do pisoteio animal, geralmente, não ultrapassam a camada de $5-10 \mathrm{~cm}$. Mesmo na camada de $0-5 \mathrm{~cm}$, quando há alteração, não atingem valores limitantes ao desenvolvimento das plantas (Conte et al. 2011).

Um fator importante no SIPA-PD é o uso de gramíneas na fase de pastagem. O sistema radicular agressivo e a alta produção de biomassa são características dessas culturas que contribuem para a manutenção da boa estrutura física do solo (Cavallini et al. 2010, Loss et al. 2011). Em sistemas como o plantio direto (12 anos), em que se tem aporte de resíduo no solo, ocorre aumento do carbono orgânico total, podendo interferir na redução da densidade do solo e no aumento da porosidade total, macro e microporosidade, na camada superficial (Marcolan \& Anghinoni 2006).

Portanto, os benefícios do SIPA-PD, para a estrutura física do solo, são refletidos no rendimento das culturas sucessoras, mesmo em sistemas com diferentes intensidades de pastejo, em que a produtividade da soja não é reduzida (Flores et al. 2007). O mesmo pode ocorrer para sistemas com diferentes estados de compactação do solo (Secco et al. 2004). Assim, avaliar a estrutura física do solo e o desenvolvimento de plantas (biomassa da parte aérea e radicular e rendimento de grãos) contribui para verificar qual a relação entre as restrições físicas do pisoteio animal e o desenvolvimento das plantas.

Existe a hipótese de que o SIPA-PD não interfere na estrutura física do solo e, consequentemente, na produtividade de soja e braquiária. Assim, objetivou-se avaliar atributos físicos do solo e a produtividade de soja e pastagem, em SIPA-PD, submetidos a diferentes intensidades de pastejo.

\section{MATERIAL E MÉTODOS}

$\mathrm{O}$ experimento foi conduzido em área experimental da Universidade Federal de Goiás (UFG), Campus Jataí (1756'57'S e 51\%43'18”'W). O solo foi classificado como Latossolo Vermelho distroférrico típico (Embrapa 2013) de textura argilosa (419 $\mathrm{g} \mathrm{kg}^{-1}$ de argila, $355 \mathrm{~g} \mathrm{~kg}^{-1}$ de silte e $226 \mathrm{~g} \mathrm{~kg}^{-1}$ de areia) e relevo levemente ondulado, localizado a $800 \mathrm{~m}$ de altitude. O clima é tropical chuvoso do tipo Aw, de acordo com a classificação de Köppen, com duas estações bem definidas, sendo uma chuvosa (outubro a abril) e outra seca (maio a setembro). A temperatura média é de $22{ }^{\circ} \mathrm{C}$ e a precipitação média anual de $1.600 \mathrm{~mm}$, podendo ocorrer veranicos (Figura 1).

A área em que o experimento foi instalado vinha sendo conduzida há vinte anos com pastagem de Urochloa decumbens, a qual não recebia correção do solo e adubação, sendo pastejada com alta intensidade por bovinos. Por ocasião da instalação do presente trabalho, a pastagem apresentava produção vegetal reduzida e a presença de plantas invasoras.

A área total do experimento é de, aproximadamente, 22 ha, a qual foi dividida em parcelas experimentais, cujo tamanho foi de cerca de 2,0 ha, dispostos em delineamento em blocos casualizados, com três repetições. Os tratamentos consistiram de diferentes alturas de manejo do pasto (P25: 0,25 m; P35: 0,35 m; e P45: 0,45 m), além de áreas controle sem pastejo (SP), entre os blocos.

O experimento iniciou-se na safra 2008/2009, com a realização de calagem, aplicando-se, a lanço, 2,5 $\mathrm{Mg} \mathrm{ha}^{-1}$ de calcário dolomítico com PRNT de

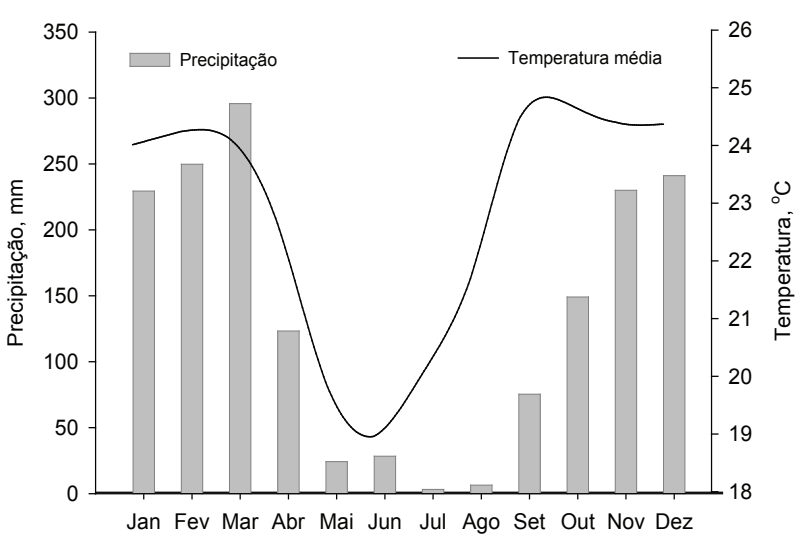

Figura 1. Temperatura média e precipitação mensal (2009 a 2012), na área experimental em Jataí (GO). Fonte: INMET (2013). 
$80 \%$, incorporado ao solo com uma aração e duas gradagens. Anualmente, desde outubro de 2009, a cultura da soja de ciclo precoce é semeada com semeadora de disco de corte e adubada com aplicação de $350 \mathrm{~kg} \mathrm{ha}^{-1}$ de adubo formulado NPK 02-18-18, espaçamento de $0,45 \mathrm{~m}$ e população aproximada de 340.000 plantas ha $^{-1}$. O manejo de pragas, adubação e colheita é realizado de forma mecânica, semelhantemente ao que ocorre em áreas de produção comercial, sendo que a colheita ocorre no início do mês de fevereiro de cada ano.

Na safra 2011/2012, foram aplicados, em área total, 2,3 $\mathrm{Mg} \mathrm{ha}^{-1}$ de calcário dolomítico, PRNT de $80 \%$, em superfície, de acordo com a análise química do solo. Após o cultivo de soja, em todas as safras, foi semeado, em linha, Urochloa ruziziensis $\left(10 \mathrm{~kg} \mathrm{ha}^{-1}\right.$ e VC $65 \%$ ). Aproximadamente 45 dias após a emergência das plantas, foi realizada a aplicação de $150 \mathrm{~kg} \mathrm{ha}^{-1}$ de nitrogênio, na forma de ureia. Essa cultura foi conduzida até o início da estação chuvosa, em outubro, sendo dessecada com a aplicação de glifosato, na dose de 4,0 L p.c. ha- ${ }^{-1}$.

Para o ciclo de pastejo, foi instalada cerca elétrica no mês de junho, 95 dias após a emergência da braquiária, em média. Os animais entraram na área quando o pasto atingiu acúmulo médio em torno de $4.000 \mathrm{~kg}$ de biomassa seca ha ${ }^{-1}$ e altura média de 1,03 m (DMS: 0,044). O pastejo iniciou-se em julho, estendendo-se até meados de outubro, totalizando 120 dias. O sistema de pastejo foi contínuo, realizado por bovinos pesando, em média, $450 \mathrm{~kg}$ de peso vivo. Foram utilizados $1,5 \mathrm{UA}$ (unidade animal) $\mathrm{ha}^{-1}$, 2,5 $\mathrm{UA} \mathrm{ha}^{-1} \mathrm{e} 3,5 \mathrm{UA} \mathrm{ha}^{-1}$, respectivamente no pastejo a $0,25 \mathrm{~m}, 0,35 \mathrm{~m}$ e $0,45 \mathrm{~m}$.

A altura do pasto, nos diferentes tratamentos, foi monitorada a cada 14 dias, com bastão graduado "swardstick" (Bircham 1981) e leituras em 50 pontos por parcela, totalizando 150 para cada tratamento. A diferença entre as alturas de pastejo desejadas foi obtida a, aproximadamente, 60 dias após a introdução dos animais, sendo adicionados ou retirados os animais reguladores, a fim de se manterem as alturas de pastejo referentes aos tratamentos adotados.

Para determinar a densidade do solo (Ds), porosidade total $(\mathrm{Pt})$, macroporosidade (Ma) e microporosidade $(\mathrm{Mi})$ do solo, foram coletadas amostras indeformadas de solo, nas safras 2010/2011 (pós-pastejo) e 2011/2012 (pós-soja e pós-pastejo), nas camadas de 0-5 cm, 5-10 cm e 10-20 cm, utilizando-se um trado tipo Uhland, com anéis metálicos e altura e diâmetro de $0,05 \mathrm{~m}$ (volume de $98 \mathrm{~cm}^{-3}$ ), em quatro pontos por parcela. A densidade do solo foi determinada pela relação entre a massa de solo seco e o volume total do solo coletado. As análises de porosidade total, macroporosidade e microporosidade foram realizadas em mesa de tensão, a $6 \mathrm{kPa}$ (Embrapa 1997).

Para a estabilidade de agregados, foram coletadas nove amostras indeformadas de solo por tratamento, nas camadas de 0-5 cm, $5-10 \mathrm{~cm}$ e $10-20 \mathrm{~cm}$, nas safras 2010/2011 (pós-pastejo) e 2011/2012 (pós-soja e pós-pastejo). As amostras foram destorroadas respeitando-se os pontos de fraqueza e secas ao ar. Em seguida, foi determinada a agregação via úmida, seguindo-se metodologia apresentada por Kemper \& Chepil (1965), com alterações propostas por Carpenedo \& Mielniczuk (1990) e Silva \& Mielniczuk (1997). Foram pesados, em duplicatas, $50 \mathrm{~g}$ de solo seco ao ar, constituído de agregados com diâmetro inferior a $9,51 \mathrm{~mm}$, os quais foram umedecidos por 12 horas e agitados por 15 minutos, a 42 oscilações por minuto. Após o peneiramento em água, obteve-se a distribuição das classes de agregados $(>4,76$; 4,76-2,0; 2,0-1,0; 1,0-0,5; 0,5-0,25; e < 0,25 mm). A partir desses dados, determinou-se o diâmetro médio ponderado (DMP), pela seguinte equação:

$$
\mathrm{DMP}=\sum_{\mathrm{i}=1}^{\mathrm{n}}(\mathrm{xi} * \mathrm{wi})
$$

em que wi é a proporção (\%) de cada classe, em relação ao total, e xi o diâmetro médio das respectivas classes (mm).

A resistência mecânica do solo à penetração foi determinada nas safras 2010/2011 (pós-pastejo) e 2011/2012 (pós-soja e pós-pastejo), segundo Manor et al. (1991), com penetrômetro digital modelo PLG1020, ponta número 2 (12,83 mm de diâmetro), cone com ângulo de $30^{\circ}$ e área da base de $130 \mathrm{~mm}$, para solos considerados "duros" (ASAE 2004). Foram medidos 220 pontos (camada de $0-20 \mathrm{~cm}$ ), espaçados em $25 \mathrm{~m}$, sendo 22 pontos por parcela para as alturas de pastejo e 11 pontos em cada faixa sem pastejo. $\mathrm{O}$ penetrômetro utilizado fez medidas a cada centímetro, sendo que foi calculada a média das leituras para os valores no intervalo das camadas apresentadas. Foi determinada, ainda, a umidade do solo, no momento das respectivas medições.

Na safra 2011/2012 (pós-soja e pós-pastejo), foi determinada a biomassa seca da parte aérea (MSPA) e de raízes (MSR) da soja e braquiária. 
$\mathrm{Na}$ cultura da soja, a coleta foi realizada em pleno florescimento e, na cultura da braquiária, no final do ciclo de pastejo. Para a MSPA, foi amostrada a parte aérea das culturas utilizando-se uma área de $1 \mathrm{~m}^{2}$, em 4 pontos por parcela, em ambas as culturas. As amostras foram secas em estufa, a $65^{\circ} \mathrm{C}$, até peso constante, e, posteriormente, pesadas, sendo os resultados expressos em $\mathrm{Mg} \mathrm{ha}^{-1}$. Já as amostras de MSR da soja e da braquiária foram coletadas com trado tipo Uhland, na camada de 0-20 cm, em anéis com altura e diâmetro de $0,1 \mathrm{~m}$, em quatro pontos por parcela. Essas amostras foram dispersas com $\mathrm{NaOH}$ $1,0 \mathrm{~mol} \mathrm{~L}^{-1}$, por uma hora, e lavadas em peneira com malha de $0,5 \mathrm{~mm}$, sendo, posteriormente, secas em estufa, a $65^{\circ} \mathrm{C}$, até peso constante, e os resultados foram apresentados em $\mathrm{Mg} \mathrm{ha}^{-1}$.

No final do ciclo da cultura da soja (safra 2011/2012), foi avaliado o rendimento de grãos, colhendo-se uma área de 4,8 $\mathrm{m}^{2}$, com quatro amostras por parcela. As amostras foram trilhadas, limpas e secas até a umidade de $130 \mathrm{~g} \mathrm{~kg}^{-1}$, para a obtenção do rendimento de grãos em $\mathrm{Mg} \mathrm{ha}{ }^{-1}$. Os resultados foram submetidos à análise de variância e as médias dos tratamentos comparadas pelo teste Tukey, a 5\% (Sisvar 2.0).

\section{RESULTADOS E DISCUSSÃO}

O pasto mantido a $0,25 \mathrm{~m}, 0,35 \mathrm{~m}$ e $0,45 \mathrm{~m}$ de altura não influenciou na densidade do solo, independentemente da camada estudada (Tabela 1). Esses resultados mostram que a força exercida pelo casco dos animais não foi suficiente para compactar o solo, no período de estudo. Ainda, os valores estão abaixo dos considerados críticos $\left(>1,40 \mathrm{Mg} \mathrm{m}^{-3}\right)$ para o desenvolvimento de plantas em Latossolos argilosos (Reinert et al. 2008).

$\mathrm{Na}$ camada de 0-5 cm, na qual é esperada maior densidade do solo, no SIPA-PD, as médias de densidade do solo, nas áreas pastejadas e sem pastejo, em todos os ciclos, foram semelhantes $\left(1,16 \mathrm{Mg} \mathrm{m}^{-3}\right)$. A densidade do solo é um atributo com baixa variabilidade (inferior a $10 \%$, neste estudo), o qual é afetado por distúrbios que causam o adensamento/ compactação do solo. Por isso, serve como referência, já que o tráfego de maquinário e o pisoteio animal são citados (Conte et al. 2011) como possíveis fatores que podem compactar o solo. Com isso, os resultados indicam que as intensidades de pastejo aplicadas não influenciaram na densidade do solo.
Tabela 1. Densidade do solo em sistema integrado de produção agropecuária em plantio direto submetido a intensidades de pastejo, em Latossolo Vermelho distroférrico, no sudoeste de Goiás.

\begin{tabular}{lccc}
\hline \multirow{2}{*}{$\begin{array}{c}\text { Intensidade } \\
\text { de pastejo }\end{array}$} & $\begin{array}{c}\text { Pós-pastejo } \\
2010 / 2011\end{array}$ & $\begin{array}{c}\text { Pós-soja } \\
2011 / 2012\end{array}$ & $\begin{array}{c}\text { Pós-pastejo } \\
2011 / 2012\end{array}$ \\
\cline { 2 - 4 } P25 & \multicolumn{3}{c}{ Densidade do solo $\left(\mathrm{Mg} \mathrm{m}^{-3}\right)$} \\
\cline { 2 - 4 } P35 & $1,03^{\text {ns }}$ & $1,12^{\text {ns }}$ & $1,24^{\text {ns }}$ \\
P45 & 1,10 & 1,14 & 1,22 \\
SP & 1,00 & 1,17 & 1,21 \\
\hline & 1,10 & 1,17 & 1,16 \\
P25 & $1,11^{\text {ns }}$ & $5-10 \mathrm{~cm}$ \\
P35 & 1,14 & $1,25^{\text {ns }}$ \\
P45 & 1,12 & 1,25 & $1,28^{\text {ns }}$ \\
SP & 1,17 & 1,27 & 1,27 \\
\hline & \multicolumn{3}{c}{1,29} \\
P25 & $0,92^{\text {ns }}$ & $10-20 \mathrm{~cm}$ & 1,25 \\
P35 & 0,98 & 1,13 & $1,14^{\text {ns }}$ \\
P45 & 0,98 & 1,11 & 1,18 \\
SP & 0,98 & 0,81 & 1,19 \\
CV (\%) & 5,34 & 5,16 & 1,20 \\
\hline
\end{tabular}

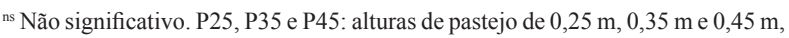
respectivamente; SP: sem pastejo.

A porosidade total foi influenciada somente após o segundo ciclo de pastejo (2011/2012), na camada de 0-5 cm (Tabela 2). Nessa camada, ocorreu redução de $10 \%$ na porosidade total, em maiores intensidades de pastejo (P25), em relação ao SP (pós-pastejo 2011/2012). No entanto, esses valores estão acima do mínimo considerado adequado ao desenvolvimento das plantas, que é de $0,50 \mathrm{~m}^{3} \mathrm{~m}^{-3}$ (Kiehl 1979). Já as intensidades baixas e moderadas de pastejo (P35 e P45) apresentaram porosidade total semelhante ao SP, demonstrando que o manejo de animais, nessas intensidades, não causa prejuízos à porosidade do solo.

A macroporosidade não foi alterada nas camadas estudadas, em função do pisoteio animal proporcionado por diferentes intensidades de pastejo (Tabela 3), estando acima do nível considerado crítico: $0,10 \mathrm{~m}^{3} \mathrm{~m}^{-3}$ (Linn \& Doran 1984). O fato de não ser observada diferença entre o P25, P35 e P45, em comparação ao SP, principalmente na camada de 0-5 cm, reforça a hipótese de que o pisoteio animal não reduz a macroporosidade do solo, nas condições deste estudo. Resultados similares foram encontrados em outros estudos realizados no Brasil (Flores et al. 2007, Lanzanova et al. 2007, Spera et al. 2010). 
Tabela 2. Porosidade total do solo em sistema integrado de produção agropecuária em plantio direto submetido a intensidades de pastejo, em Latossolo Vermelho distroférrico, no sudoeste de Goiás.

\begin{tabular}{|c|c|c|c|}
\hline \multirow{2}{*}{$\begin{array}{l}\text { Intensidade } \\
\text { de pastejo }\end{array}$} & $\begin{array}{c}\text { Pós-pastejo } \\
\text { 2010/2011 }\end{array}$ & $\begin{array}{c}\text { Pós-soja } \\
\text { 2011/2012 }\end{array}$ & $\begin{array}{c}\text { Pós-pastejo } \\
2011 / 2012 \\
\end{array}$ \\
\hline & \multicolumn{3}{|c|}{ Porosidade total $\left(\mathrm{m}^{3} \mathrm{~m}^{-3}\right)$} \\
\hline & \multicolumn{3}{|c|}{$0-5 \mathrm{~cm}-$} \\
\hline $\mathrm{P} 25$ & $0,61^{\mathrm{ns}}$ & $0,60^{\text {ns }}$ & $0,56 b^{*}$ \\
\hline P35 & 0,60 & 0,60 & $0,58 \mathrm{ab}$ \\
\hline P45 & 0,61 & 0,59 & $0,62 \mathrm{a}$ \\
\hline \multirow[t]{2}{*}{ SP } & 0,61 & 0,57 & $0,62 \mathrm{a}$ \\
\hline & \multicolumn{3}{|c|}{$5-10 \mathrm{~cm}$} \\
\hline $\mathrm{P} 25$ & $0,58^{\mathrm{ns}}$ & $0,56^{\mathrm{ns}}$ & $0,56^{\text {ns }}$ \\
\hline P35 & 0,58 & 0,58 & 0,56 \\
\hline P45 & 0,57 & 0,56 & 0,60 \\
\hline \multirow[t]{2}{*}{ SP } & 0,56 & 0,60 & 0,61 \\
\hline & \multicolumn{3}{|c|}{$10-20 \mathrm{~cm}$} \\
\hline $\mathrm{P} 25$ & $0,57^{\mathrm{ns}}$ & $0,56^{\mathrm{ns}}$ & $0,58^{\text {ns }}$ \\
\hline P35 & 0,59 & 0,59 & 0,57 \\
\hline P45 & 0,61 & 0,57 & 0,60 \\
\hline SP & 0,54 & 0,60 & 0,61 \\
\hline CV (\%) & 4,46 & 3,51 & 2,79 \\
\hline
\end{tabular}

* Médias seguidas de letras iguais, nas colunas, para a mesma camada de solo, não diferem entre si, pelo teste Tukey $(\mathrm{p}<0,05)$; ${ }^{\text {ns }}$ não significativo. P25, P35 e P45: alturas de pastejo de $0,25 \mathrm{~m}, 0,35 \mathrm{~m}$ e $0,45 \mathrm{~m}$, respectivamente; $\mathrm{SP}$ : sem pastejo.

Tabela 3. Macroporosidade do solo em sistema integrado de produção agropecuária em plantio direto submetido a intensidades de pastejo, em Latossolo Vermelho distroférrico, no sudoeste de Goiás.

\begin{tabular}{lccc}
\hline \multirow{2}{*}{$\begin{array}{c}\text { Intensidade } \\
\text { de pastejo }\end{array}$} & $\begin{array}{c}\text { Pós-pastejo } \\
2010 / 2011\end{array}$ & $\begin{array}{c}\text { Pós-soja } \\
2011 / 2012\end{array}$ & $\begin{array}{c}\text { Pós-pastejo } \\
2011 / 2012\end{array}$ \\
\cline { 2 - 4 } Pacroporosidade $\left(\mathrm{m}^{3} \mathrm{~m}^{-3}\right)$ \\
\cline { 2 - 4 } P25 & $0,29^{\mathrm{ns}}$ & $0,5 \mathrm{~cm}$ & $0,17^{\mathrm{ns}}$ \\
P35 & 0,26 & 0,18 & 0,17 \\
P45 & 0,29 & 0,23 & 0,19 \\
SP & 0,25 & 0,20 & 0,21 \\
\hline & \multicolumn{3}{c}{} \\
P25 & $0,25^{\text {ns }}$ & $0,18^{\mathrm{ns}}$ & $0,18^{\mathrm{ns}}$ \\
P35 & 0,24 & 0,17 & 0,16 \\
P45 & 0,24 & 0,20 & 0,15 \\
SP & 0,21 & 0,18 & 0,18 \\
\hline & \multicolumn{3}{c}{$0,20 \mathrm{~cm}$} \\
P25 & $0,29^{\text {ns }}$ & $0,22^{\mathrm{ns}}$ & $0,25^{\mathrm{ns}}$ \\
P35 & 0,30 & 0,21 & 0,22 \\
P45 & 0,30 & 0,24 & 0,20 \\
SP & 0,26 & 0,24 & 0,20 \\
CV (\%) & 9,78 & 9,77 & 11,06 \\
\hline
\end{tabular}

ns Não significativo. P25, P35 e P45: alturas de pastejo de $0,25 \mathrm{~m}, 0,35 \mathrm{~m}$ e $0,45 \mathrm{~m}$, respectivamente; SP: sem pastejo.
Sabe-se que o efeito do pisoteio animal, quando ocorre, está relacionado com a alta umidade do solo e é concentrado na camada superficial, em função da pequena área do casco animal e do alto peso exercido sobre o solo (Flores et al. 2007). Durante o ciclo de pastejo, a umidade do solo foi baixa, em função da baixa precipitação nessa região (Figura 1). Essa baixa umidade do solo pode ter contribuído para o menor efeito do pisoteio animal.

A microporosidade não se alterou em função do pisoteio animal proporcionado por diferentes intensidades de pastejo em nenhum dos ciclos de pastejo e soja, nas camadas estudadas (Tabela 4). Resultados similares foram observados por Lanzanova et al. (2007). A não interferência das intensidades de pastejo nesse atributo é relevante, já que a microporosidade contribui para a retenção e disponibilidade de água no solo, reduzindo os riscos frente a períodos de seca, além de aumentar a absorção de nutrientes pelas raízes das plantas. A microporosidade, geralmente, não é alterada pela ação antrópica (Viana et al. 2011). Porém, quando alterada, pode significar quebra de agregados, redução do armazenamento e disponibilidade de água no solo, interferindo na

Tabela 4. Microporosidade do solo em sistema integrado de produção agropecuária em plantio direto submetido a intensidades de pastejo, em Latossolo Vermelho distroférrico, no sudoeste de Goiás.

\begin{tabular}{|c|c|c|c|}
\hline \multirow{2}{*}{$\begin{array}{l}\text { Intensidade } \\
\text { de pastejo }\end{array}$} & $\begin{array}{c}\text { Pós-pastejo } \\
2010 / 2011 \\
\end{array}$ & $\begin{array}{c}\text { Pós-soja } \\
2011 / 2012 \\
\end{array}$ & $\begin{array}{c}\text { Pós-pastejo } \\
2011 / 2012 \\
\end{array}$ \\
\hline & \multicolumn{3}{|c|}{ Microporosidade $\left(\mathrm{m}^{3} \mathrm{~m}^{-3}\right)$} \\
\hline \multirow[b]{2}{*}{ D25 } & \multicolumn{3}{|c|}{$-0-5 \mathrm{~cm}$} \\
\hline & $0,32^{\text {ns }}$ & $0,38^{\mathrm{ns}}$ & $0,39^{\text {ns }}$ \\
\hline P35 & 0,34 & 0,41 & 0,40 \\
\hline $\mathrm{P} 45$ & 0,32 & 0,36 & 0,43 \\
\hline \multirow[t]{2}{*}{ SP } & 0,36 & 0,36 & 0,41 \\
\hline & \multicolumn{3}{|c|}{$5-10 \mathrm{~cm}$} \\
\hline $\mathrm{P} 25$ & $0,33^{\mathrm{ns}}$ & $0,38^{\mathrm{ns}}$ & $0,38^{\mathrm{ns}}$ \\
\hline P35 & 0,33 & 0,41 & 0,39 \\
\hline $\mathrm{P} 45$ & 0,33 & 0,36 & 0,45 \\
\hline \multirow[t]{2}{*}{ SP } & 0,35 & 0,40 & 0,43 \\
\hline & \multicolumn{3}{|c|}{$-10-20 \mathrm{~cm}$} \\
\hline $\mathrm{P} 25$ & $0,28^{\mathrm{ns}}$ & $0,34^{\mathrm{ns}}$ & $0,36^{\text {ns }}$ \\
\hline P35 & 0,30 & 0,38 & 0,35 \\
\hline $\mathrm{P} 45$ & 0,31 & 0,32 & 0,42 \\
\hline SP & 0,28 & 0,33 & 0,41 \\
\hline $\mathrm{CV}(\%)$ & 5,12 & 7,28 & 6,13 \\
\hline
\end{tabular}


biota do solo pela redução da atividade de bactérias e outros organismos.

O diâmetro médio ponderado de agregados, nas áreas pastejadas, é inferior ao encontrado no SP, nas camadas de $0-5 \mathrm{~cm}$ e $10-20 \mathrm{~cm}$, no primeiro ciclo de pastejo (2010/2011) (Tabela 5). Esse resultado pode estar relacionado à proximidade do revolvimento do solo, para implantar o SIPA-PD, mostrando que pode ser necessário um período maior, antes da entrada de animais em áreas com revolvimento do solo. O revolvimento do solo interfere na estabilidade dos agregados, já que práticas como a aração e a gradagem provocam a desestruturação dos agregados e a oxidação da matéria orgânica (Rozane et al. 2010) e tem influência direta na uniformização dos dados de porosidade apresentados.

Na safra 2011/2012 (pós-soja e pós-pastejo), as intensidades de pastejo não diferiram da área sem pastejo. Estudos de longo prazo tem mostrado maior diâmetro médio ponderado em áreas pastejadas, em função de o pisoteio dos animais aproximar as partículas (Conte et al. 2011). Porém, a maior agregação só ocorre se a quantidade de raízes e de matéria orgânica for suficiente para agregar o solo e o mesmo

Tabela 5. Diâmetro médio ponderado em sistema integrado de produção agropecuária em plantio direto submetido a intensidades de pastejo, em Latossolo Vermelho distroférrico, no sudoeste de Goiás.

\begin{tabular}{lccc}
\hline \multirow{2}{*}{$\begin{array}{c}\text { Intensidade } \\
\text { de pastejo }\end{array}$} & $\begin{array}{c}\text { Pós-pastejo } \\
2010 / 2011\end{array}$ & $\begin{array}{c}\text { Pós-soja } \\
2011 / 2012\end{array}$ & $\begin{array}{c}\text { Pós-pastejo } \\
2011 / 2012\end{array}$ \\
\cline { 2 - 4 } & \multicolumn{3}{c}{ Diâmetro médio ponderado $(\mathrm{mm})$} \\
\hline & \multicolumn{4}{c}{$0-5 \mathrm{~cm}$} \\
P25 & $1,81 \mathrm{ab}^{*}$ & $1,94^{\text {ns }}$ & $2,23^{\text {ns }}$ \\
P35 & $1,67 \mathrm{~b}$ & 2,14 & 2,10 \\
P45 & $1,83 \mathrm{ab}$ & 2,20 & 2,15 \\
SP & $2,18 \mathrm{a}$ & 1,85 & 2,20 \\
\hline & & $5-10 \mathrm{~cm}$ & \\
P25 & $2,11^{\text {ns }}$ & $2,38^{\text {ns }}$ & $2,27^{\text {ns }}$ \\
P35 & 2,11 & 2,27 & 2,23 \\
P45 & 2,14 & 2,49 & 2,25 \\
SP & 2,08 & 2,18 & 2,36 \\
\hline & & $10-20 \mathrm{~cm}$ & \\
P25 & $2,10 \mathrm{ab}$ & $2,33^{\text {ns }}$ & $2,27^{\text {ns }}$ \\
P35 & $1,97 \mathrm{~b}$ & 2,39 & 2,17 \\
P45 & $1,98 \mathrm{ab}$ & 2,40 & 2,19 \\
SP & $2,29 \mathrm{a}$ & 2,27 & 2,26 \\
CV (\%) & 7,16 & 5,79 & 2,43 \\
\hline
\end{tabular}

* Médias seguidas de letras iguais, nas colunas, para a mesma camada de solo, não diferem entre si, pelo teste Tukey $(\mathrm{p}<0,05)$; ${ }^{\text {ns }}$ não significativo. P25, P35 e P45: alturas de pastejo de $0,25 \mathrm{~m}, 0,35 \mathrm{~m}$ e $0,45 \mathrm{~m}$, respectivamente; $\mathrm{SP}$ : sem pastejo. não se desestruturar. A agregação ocorre devido à liberação de compostos produzidos pela raiz, como o ácido poligalacturônico, que atua na estabilidade dos agregados, aumentando a força de ligação entre as partículas, e por redução da sua velocidade de umedecimento, preservando-os, dessa forma, da destruição, quando em contato com a água (Ragassi 2009). Esse fato pode justificar os resultados, já que, neste estudo, somente as análises com maior proximidade ao revolvimento foram alteradas pelo pisoteio animal.

A partir do segundo ciclo, não se observou diferença na agregação do solo. Neste estudo, os valores obtidos para diâmetro médio ponderado não ultrapassaram 2,50 mm, sendo inferiores aos obtidos por Conte et al. (2011), em Latossolo Vermelho distróférrico típico, e por Salton et al. (2008), em diferentes Latossolos.

$\mathrm{Na}$ análise de resistência mecânica à penetração, não houve diferenças de umidade entre os tratamentos, nas diferentes safras, e as médias de umidade do solo foram de $22,8 \mathrm{~m}^{3} \mathrm{~m}^{-3}$ (pós-pastejo 2010/2011; CV 8,87\%); 20,2 $\mathrm{m}^{3} \mathrm{~m}^{-3}$ (pós-soja 2011/2012; CV 9,38 \%); e 27,3 $\mathrm{m}^{3} \mathrm{~m}^{-3}$ (pós-pastejo 2011/2012; CV 6,37 \%), estando abaixo da capacidade de campo de $0,38 \mathrm{~m}^{3} \mathrm{~m}^{-3}$, citada por Serafim et al. (2008), para Latossolo Vermelho distroférrico.

A resistência mecânica à penetração aumentou na camada de $0-5 \mathrm{~cm}$, em função das intensidades de pastejo (pós-pastejo 2010/2011 e 2011/2012), concordando com Conte et al. (2011). Esse aumento na camada de $0-5 \mathrm{~cm}$ foi maior no pastejo intenso (P25), diferindo do P35 e sem pastejo (Tabela 6). Esse resultado pode estar relacionado à menor quantidade de resíduo sobre o solo, pois, segundo Bono et al. (2013), os resíduos aumentam o teor de matéria orgânica, protegendo-o, assim, da ação compressiva e cisalhante dos cascos dos animais. Nessa mesma camada, no pós-soja 2011/2012, não foi verificado aumento significativo de resistência mecânica à penetração, entre as áreas onde é realizado o pastejo e as que não são pastejadas. Nesse ciclo, não há presença de animais em pastejo, mas o tráfego de maquinário é maior. Entretanto, esse fato não significou aumento de resistência mecânica à penetração, assim como as possíveis consequências das alterações da fase de pastejo, com a ressalva de que não foi amostrado na linha do tráfego.

A resistência mecânica à penetração é importante, pois pode interferir na taxa de elongação das 
raízes de plantas, mesmo em condições adequadas de disponibilidade de água. Na camada de $5-10 \mathrm{~cm}$, os resultados mostraram P25 com maior resistência mecânica à penetração, em relação ao P35 (pós-pastejo 2010/2011), SP (pós-soja 2011/2012) e P35, P45 e SP (pós-pastejo 2011/2012). Na camada de 10-20 cm, o P25 teve maior RP, em relação ao SP (pós-soja 2011/2012). Os resultados de RP mostraram que a camada de $5-10 \mathrm{~cm}$ pode sofrer interferência do pisoteio animal, já que o P25 sempre apresentou maior resistência mecânica à penetração. No entanto, as alterações na resistência

Tabela 6. Resistência mecânica à penetração do solo sob plantio direto submetido a intensidades de pastejo em sistema integrado de produção agropecuária, em Latossolo Vermelho distroférrico, no sudoeste de Goiás.

\begin{tabular}{|c|c|c|c|}
\hline \multirow{2}{*}{$\begin{array}{l}\text { Intensidade } \\
\text { de pastejo }\end{array}$} & $\begin{array}{c}\text { Pós-pastejo } \\
2010 / 2011\end{array}$ & $\begin{array}{c}\text { Pós-soja } \\
2011 / 2012\end{array}$ & $\begin{array}{c}\text { Pós-pastejo } \\
2011 / 2012\end{array}$ \\
\hline & \multicolumn{3}{|c|}{ Resistência à penetração $(\mathrm{MPa})$} \\
\hline & \multicolumn{3}{|c|}{$0-5 \mathrm{~cm} \longrightarrow$} \\
\hline P25 & $1,69 a^{*}$ & $1,64^{\mathrm{ns}}$ & $1,88 \mathrm{a}$ \\
\hline P35 & $1,22 \mathrm{~b}$ & 1,49 & 1,41 bc \\
\hline P45 & $1,48 \mathrm{ab}$ & 1,49 & $1,64 \mathrm{ab}$ \\
\hline SP & $1,31 \mathrm{~b}$ & 1,34 & $1,25 \mathrm{c}$ \\
\hline & \multicolumn{3}{|c|}{$5-10 \mathrm{~cm}$} \\
\hline P25 & $1,79 \mathrm{a}$ & $2,02 \mathrm{a}$ & $1,81 \mathrm{a}$ \\
\hline P35 & $1,52 \mathrm{~b}$ & $1,59 \mathrm{c}$ & $1,72 \mathrm{ab}$ \\
\hline P45 & $1,76 \mathrm{a}$ & $1,78 \mathrm{~b}$ & $1,81 \mathrm{ab}$ \\
\hline SP & $1,62 \mathrm{ab}$ & $1,48 \quad \mathrm{c}$ & $1,61 \mathrm{~b}$ \\
\hline & \multicolumn{3}{|c|}{$10-20 \mathrm{~cm}$} \\
\hline P25 & $1,68^{\mathrm{ns}}$ & $1,68 \mathrm{a}$ & $1,73^{\mathrm{ns}}$ \\
\hline P35 & 1,68 & $1,54 \mathrm{ab}$ & 1,76 \\
\hline P45 & 1,71 & $1,73 \mathrm{a}$ & 1,77 \\
\hline SP & 1,65 & $1,38 \mathrm{~b}$ & 1,73 \\
\hline CV (\%) & 9,00 & 6,68 & 9,01 \\
\hline
\end{tabular}

* Médias seguidas de letras iguais, nas colunas, para a mesma camada de solo, não diferem entre si, pelo teste Tukey ( $\mathrm{p}<0,05)$; ${ }^{\mathrm{ns}}$ não significativo. P25, P35 e P45: alturas de pastejo de $0,25 \mathrm{~m}, 0,35 \mathrm{~m}$ e $0,45 \mathrm{~m}$, respectivamente; $\mathrm{SP}$ : sem pastejo. mecânica à penetração ficaram abaixo do valor crítico: geralmente $2 \mathrm{MPa}$ (Taylor et al. 1966). Frente aos recentes estudos indicando que uma maior aproximação das partículas pode significar maior contato solo/raiz (Mazurana et al. 2013, Stone et al. 2002), esse fato pode ser benéfico para as plantas, principalmente a longo prazo, desde que não atinja os valores críticos para o desenvolvimento e crescimento das plantas.

$\mathrm{Na}$ avaliação da safra 2011/2012 (pós-soja e pós-pastejo), a biomassa seca da parte aérea de braquiária e a biomassa seca total (soja + braquiária) foram alteradas, em função das intensidades de pastejo (Tabela 7). Espera-se que em um sistema com diferentes intensidades de pastejo ocorram diferenças no resíduo remanescente do pasto, ao final do ciclo de pastejo, como observado neste estudo (P25 < $\mathrm{P} 35<\mathrm{P} 45<\mathrm{SP})$. Esse fato foi decisivo, também, para o resultado de biomassa seca total, seguindo a mesma tendência. Os valores de biomassa seca total variaram de $23 \mathrm{Mg} \mathrm{ha}^{-1}$ a $30 \mathrm{Mg} \mathrm{ha}^{-1}$, valores esses adicionados ao sistema, em uma safra de cultivo (soja + braquiária).

Analisando-se apenas as intensidades de pastejo moderado e a área sem pastejo, não se verificou diferença para biomassa seca total. Esse resultado mostra que um pastejo moderado não afeta a produção de massa seca no sistema, após os ciclos de cultivos. Já a maior intensidade reduziu a biomassa seca total, muito em função do consumo da forrageira pelos animais. A adição de $23 \mathrm{Mg}$ ha $^{-1}$ de massa seca é dividida entre soja e braquiária, com $9 \mathrm{Mg} \mathrm{ha}^{-1} \mathrm{e}$ $14 \mathrm{Mg} \mathrm{ha}^{-1}$, respectivamente, mostrando que ocorre adição de resíduo com baixa e alta relação $\mathrm{C} / \mathrm{N}$. Esse fato é importante para a reposição de carbono a curto, médio e longo prazo. Pode ser verificado, também,

Tabela 7. Produtividade de soja, biomassa seca da parte aérea (MSPA) e massa seca de raízes (MSR) de Urochloa ruziziensis e soja, na safra 2011/2012 (pós-soja e pós pastejo), em sistema integrado de produção agropecuária em plantio direto submetido a intensidades de pastejo, em Latossolo Vermelho distroférrico, no sudoeste de Goiás.

\begin{tabular}{|c|c|c|c|c|c|c|}
\hline Manejo & $\begin{array}{c}\text { MSPA } \\
\text { soja }\end{array}$ & $\begin{array}{c}\text { MSR Soja } \\
0-20 \mathrm{~cm}\end{array}$ & $\begin{array}{c}\text { Produtividade } \\
\text { de soja }\end{array}$ & $\begin{array}{c}\text { MSPA }^{(1)} \\
\text { braquiária }\end{array}$ & $\begin{array}{c}\text { MSR braquiária } \\
0-20 \mathrm{~cm}\end{array}$ & MS total \\
\hline & & & & & & \\
\hline P25 & $6,10^{\mathrm{ns}}$ & $2,89^{\text {ns }}$ & $3,47^{\mathrm{ns}}$ & $6,94 * \quad d$ & $7,80^{\mathrm{ns}}$ & $23,75 \mathrm{~b}$ \\
\hline P35 & 6,10 & 2,48 & 3,42 & $8,86 \quad \mathrm{c}$ & 7,60 & $25,07 \mathrm{ab}$ \\
\hline P45 & 6,05 & 2,77 & 3,76 & $11,21 \quad b$ & 8,96 & $29,01 \mathrm{ab}$ \\
\hline SP & 6,19 & 2,54 & 3,67 & $13,66 \mathrm{a}$ & 8,40 & $30,80 \mathrm{a}$ \\
\hline CV $(\%)$ & 6,97 & 22,67 & 7,63 & 3,84 & 22,46 & 7,75 \\
\hline
\end{tabular}

* Médias seguidas de mesma letra, na coluna (pastejo), não diferem pelo teste Tukey ( $<0,05$ ); ns não significativo. P25, P35 e P45: alturas de pastejo de 0,25 m, 0,35 m e $0,45 \mathrm{~m}$, respectivamente; SP: sem pastejo. ${ }^{(1)}$ Coletada no final de cada ciclo. 
que parte desse incremento está em subsuperfície, contribuindo, assim, a médio e longo prazo, para uma maior estruturação do solo, principalmente por meio da agregação.

Não houve interferência das intensidades de pastejo no desenvolvimento de raízes de soja e braquiária, como mostrado pela massa seca de raízes (Tabela 7). Esse resultado corrobora a maioria das análises físicas realizadas neste estudo, evidenciando que o pisoteio de animais, nas condições deste estudo, não altera a estrutura do solo de forma a reduzir o desenvolvimento das plantas.

Em relação à produtividade de grãos de soja, também não se verificou diferença, comparando-se as áreas com e sem pastejo (Tabela 7). As áreas pastejadas produziram, em média, $3,55 \mathrm{Mg} \mathrm{ha}^{-1}$, e a sem pastejo 3,67 $\mathrm{Mg} \mathrm{ha}^{-1}$. Nunes et al. (2006) citam que os melhores resultados de produtividade de leguminosa (feijão), em solo arenoso, foram obtidos nos tratamentos de gramíneas, com destaque para Urochloa brizantha $\mathrm{cv}$. Marandu (massa seca de $6.200 \mathrm{~kg} \mathrm{ha}^{-1}$ ) e Urochloa decumbens cv. Basilisk (massa seca de $11.173 \mathrm{~kg} \mathrm{ha}^{-1}$ ). Esse resultado reforça a tese de que a presença de animais, neste estudo, não interfere de forma a degradar a estrutura física do solo, fato comprovado pela não redução da produtividade de grãos de soja.

\section{CONCLUSÕES}

1. O sistema integrado de produção agropecuária em plantio direto pode ser utilizado sem riscos aos atributos físicos do solo, desde que conduzido em intensidades moderadas de pastejo (altura de manejo do pasto de $0,35 \mathrm{~m}$ e $0,45 \mathrm{~m}$ ), pois, nas condições deste estudo, pouco alterou os atributos físicos do solo e, quando alterou, não atingiu os valores considerados críticos para o desenvolvimento de plantas.

2. O pastejo mantido a $0,25 \mathrm{~m}$ altera a porosidade total do solo, aumenta a sua resistência mecânica à penetração e reduz o aporte de biomassa seca da parte aérea, mesmo sendo esta considerada alta. Porém, o pasto mantido a $0,25 \mathrm{~m}$ não interfe na produtividade da soja.

3. As intensidades de pastejo no sistema integrado de produção agropecuária em plantio direto adicionam quantidades diferentes de biomassa seca de braquiária (parte aérea) e quantidades semelhantes de biomassa da raiz (subsuperfície).

\section{REFERÊNCIAS}

AMERICAN SOCIETY OF AGRICULTURAL ENGINEERS (ASAE). Soil cone penetrometer - ASAE S313.3. St. Joseph: ASAE, 2004.

BIRCHAM, J. S. Herbage growth and utilization under continuous stocking management. 1981. $384 \mathrm{f}$. Thesis (Ph.D in Computer Science) - University of Edinburgh, Edinburgh, 1981.

BONO, J. A. et al. Qualidade física do solo em um Latossolo Vermelho da região sudoeste dos Cerrados sob diferentes sistemas de uso e manejo. Revista Brasileira de Ciência do Solo, Viçosa, v. 37, n. 3, p. 743-753, 2013.

CARPENEDO, V.; MIELNICZUK, J. Estado de agregação e qualidade de agregados de Latossolos Roxos, submetidos a diferentes sistemas de manejo. Revista Brasileira de Ciência do Solo, Campinas, v. 14, n. 1, p. 99-105, 1990.

CAVALLINI, M. C. et al. Relações entre produtividade de Brachiaria brizantha e atributos físicos de um Latossolo do Cerrado. Revista Brasileira de Ciência do Solo, Viçosa, v. 34, n. 4, p. 1007-1015, 2010.

CONTE, O. et al. Evolução de atributos físicos de solo em sistema de integração lavoura pecuária. Pesquisa Agropecuária Brasileira, Brasília, DF, v. 46, n. 10, p. 13011309, 2011.

EMPRESA BRASILEIRA DE PESQUISA AGROPECUÁRIA (Embrapa). Centro Nacional de Pesquisa de Solos. Manual de métodos de análises de solo. Rio de Janeiro: Embrapa, 1997.

EMPRESA BRASILEIRA DE PESQUISA AGROPECUÁRIA (Embrapa). Centro Nacional de Pesquisa de Solos. Sistema brasileiro de classificação de solos. 3. ed. Rio de Janeiro: Embrapa, 2013.

FLORES, J. P. C. et al. Atributos físicos do solo e rendimento de soja em sistema plantio direto em integração lavoura pecuária com diferentes pressões de pastejo. Revista Brasileira de Ciências do Solo, Viçosa, v. 31, n. 4, p. 771-780, 2007.

HALLETT, P. D. et al. Plant influence on rhizosphere hydraulic properties: direct measurements using a miniaturized infiltrometer. New Phytologist, Bristol, v. 157, n. 3, p. 597-603, 2003.

INSTITUTO NACIONAL DE METEOROLOGIA (INMET). Dados da rede do INMET. 2013. Disponível em: <http://www.inmet.gov.br/projetos/rede/pesquisa/ gera_serie_txt mensal.php?\&m RelEstacao $=83464 \& b t$ nProcesso $=$ serie $\&$ melDtInicio $=01 / 01 / 2003 \& \mathrm{mRelDtF}$ $\mathrm{im}=31 / 12 / 2012 \& \mathrm{~m}$ Atributos $>$. Acesso em: 28 fev. 2013. 
KEMPER, W. D.; CHEPIL, W. S. Size distribution of aggregation. In.: BLACK, C. A. (Eds.). Methods of soil analysis. Madison: American Society of Agronomy, 1965. p. 499-510.

KIEHL, E. J. Manual de edafologia. São Paulo: Agronômica Ceres, 1979.

LANZANOVA, M. E. et al. Atributos físicos do solo em sistema de integração lavoura-pecuária em plantio direto. Revista Brasileira de Ciência do Solo, Viçosa, v. 31, n. 5, p. 1131-1140, 2007.

LINN, D. M.; DORAN, J. W. Effect of water-filled pore space on carbon dioxide and nitrous oxide production in tilled and non tilled soils. Soil Science Society of America Journal, Amsterdam, v. 48, n. 6, p. 1267-1272, 1984.

LOSS, A. et al. Agregação, carbono e nitrogênio em agregados do solo em plantio direto com integração lavoura-pecuária. Pesquisa Agropecuária Brasileira, Brasília, DF, v. 46, n. 10, p. 1269-1276, 2011.

MANOR, G. et al. Soil cone index variability under fixed traffic tillage systems. Transactions of the ASAE, Cambridge, v. 34, n. 5, p. 1952-1956, 1991.

MARCOLAN, A. L.; ANGHINONI, I. Atributos físicos de um Argissolo e rendimento de culturas de acordo com o revolvimento do solo em plantio direto. Revista Brasileira de Ciência do Solo, Viçosa, v. 30, n. 1, p. 163-170, 2006.

MAZURANA, M. et al. Propriedades físicas do solo e crescimento de raízes de milho em um Argissolo Vermelho sob tráfego controlado de máquinas. Revista Brasileira de Ciência do Solo, Viçosa, v. 37, n. 3, p. 1185-1195, 2013.

NUNES, U. R. et al. Produção de palhada de plantas de cobertura e rendimento de feijão em plantio direto. Pesquisa Agropecuária Brasileira, Brasília, DF, v. 41, n. 6, p. 943-948, 2006.

RAGASSI, F. C. Sistema de preparo profundo de solo e sucessão de gramíneas para o plantio da batata. 2009. 82 f. Dissertação (Mestrado em Agronomia) - Escola Superior de Agricultura Luiz de Queiroz, Universidade de São Paulo, Piracicaba, 2009.

REINERT, J. D. et al. Limites críticos de densidade do solo para o crescimento de raízes de plantas de cobertura em Argissolo Vermelho. Revista Brasileira de Ciência do Solo, Viçosa, v. 32, n. 5, p. 1805-1816, 2008.

ROZANE, D. E. et al. Estoque de carbono e estabilidade de agregados de um Latossolo Vermelho distroférrico, sob diferentes manejos. Bioscience Journal, Uberlândia, v. 26, n. 1, p. 24-32, 2010.

SALTON, J. C. et al. Agregação e estabilidade de agregados do solo em sistemas agropecuários em Mato Grosso do Sul. Revista Brasileira de Ciência do Solo, Viçosa, v. 32, n. 1, p. 11-21, 2008.

SECCO, D. et al. Produtividade de soja e propriedades físicas de um Latossolo submetido a sistemas de manejo e compactação. Revista Brasileira de Ciência do Solo, Viçosa, v. 28, n. 5, p. 797-804, 2004.

SERAFIM, M. E. et al. Intervalo hídrico ótimo em um Latossolo Vermelho distroférrico sob diferentes sistemas de produção. Engenharia Agrícola, Jaboticabal, v. 28, n. 4, p. 654-665, 2008.

SILVA, I. F.; MIELNICZUK, J. Avaliação do estado de agregação do solo afetado pelo uso agrícola. Revista Brasileira de Ciência do Solo, Viçosa, v. 21, n. 2, p. 313319, 1997.

SOUZA, E. D. et al. Soil aggregation in a crop-livestock integration system under no-tillage. Revista Brasileira de Ciência do Solo, Viçosa, v. 34, n. 4, p. 1365-1374, 2010.

SPERA, S. T. et al. Efeito de integração entre lavoura e pecuária sob plantio direto, em alguns atributos físicos do solo após dez anos. Bragantia, Campinas, v. 69, n. 3, p. $695-704,2010$

STONE, L. F. et al. Compactação do solo na cultura do feijoeiro (Phaseolus vulgaris L.): I. Efeito nas propriedades físico-hídricas do solo. Revista Brasileira de Engenharia Agrícola e Ambiental, Campina Grande, v. 6, n. 2, p. 207-212, 2002.

TAYLOR, H. M. et al. Soil strength-root penetration relations for medium to coarse-textured soil materials. Soil Science, Baltimore, v. 102, n. 1, p. 18-22, 1966.

VIANA, E. T. et al. Atributos físicos e carbono orgânico em Latossolo Vermelho sob diferentes sistemas de uso e manejo. Revista Brasileira de Ciência do Solo, Viçosa, v. 35, n. 6, p. 2105-2114, 2011. 